Bangladesh J. Bot. 50(3): 781-794, 2021 (September) SpecialＤOI: https://doi.org/10.3329/bjb.v50i5.56429

\title{
EFFECTS OF DIFFERENT FERTILIZER APPLICATION PRACTICES ON NEWLY RECLAIMED SOIL STRUCTURE AND ITS NUTRIENT CONTENT
}

\author{
Zhe Liu ${ }^{1,2,3}$, Zenghui Sun ${ }^{1,2,3 *}$, Huanyuan Wang ${ }^{1,2,3}$, Yang Zhang ${ }^{1,2,3}$, \\ Tianqing Chen ${ }^{1,2,3}$, Cunhu Wang ${ }^{1,2,3}$ and Jianfeng Li $^{1,2,3}$ \\ Shaanxi Provincial Land Engineering Construction Group Co. Ltd., \\ $X i$ 'an 710075, China
}

Keywords: Fertilization application practices, Newly reclaimed cultivated land, Soil organic matter, Aggregates stability, Soil microstructure

\begin{abstract}
Effects of organic fertilizer practice (OF), organic fertilizer combined with chemical fertilizer practice (OC), and conventional fertilization practice (CF) on soil structure were evaluated by combining micro and macro analyses in newly reclaimed cultivated land. Soil organic matter (SOM), cation exchange capacity (CEC), soil bulk density (BD), soil moisture content (SMC), and aggregate stability were also analyzed. The CF soil structure was mainly composed of moderately separated block and angular structures with the minimum SOM $(7.08 \mathrm{~g} / \mathrm{kg})$ and the highest BD $\left(1.40 \mathrm{~g} / \mathrm{cm}^{3}\right)$, and the pore type was mainly simple surface cracks. Compared with CF, OF and OC significantly increased SOM content by 59.3 and $29.6 \%$ (p < 0.05 ) and CEC by 13.5 and $5.2 \%$, respectively. The newly reclaimed soil structure was improved to a moderately separated clump structure and a well-developed aggregated structure, and the number of composite accumulation pores gradually increased. Moreover, OF and OC were associated with higher mean weight diameter (MWD), geometric mean diameter (GMD) values, and lower BD and fractal dimension $(D)$ values. The water-stable macroaggregates $\left(R_{0.25}\right)$ and the aggregate stability of newly reclaimed soil were significantly increased, with a stronger improvement observed under OF. These results confirm the benefits of $\mathrm{OC}$ and $\mathrm{OF}$ practices on the structural stability, water and fertilizer retention characteristics of newly reclaimed cultivated land, and will be conductive to improving the soil quality and achieving sustainable soil development.
\end{abstract}

\section{Introduction}

With the acceleration of China's industrialization and urbanization, China is facing serious problems related to the drastic decrease in the amount of arable land and intensified conflicts between people and land. In order to supplement arable land resources and ensure food security, China has carried out a large number of land consolidation projects (Liu 2018, Liu et al. 2018). However, the newly reclaimed land has problems such as less soil maturity, poor soil structure, and low productivity, which limits the availability of newly reclaimed soil. Therefore, it is important to determine how to improve the soil quality of the newly reclaimed cultivated land to achieve increased productivity ( $\mathrm{Hu}$ et al. 2010, Liu et al. 2016). Fertilization is one of the key agricultural management measures that affect soil properties and crop growth and development. Long-term fertilization measures not only affect soil fertility and land productivity, but also play an important role in the soil health and sustainable development of soil (Sainju 2006, Celik et al. 2010, Mikha and Rice 2014). Common agricultural production practices typically result in the abuse of chemical fertilizers, which not only causes damage to the soil aggregate structure and soil

*Author for correspondence: <liuzhe168@126.com>. ${ }^{1}$ Institute of Land Engineering and Technology, Shaanxi Provincial Land Engineering Construction Group Co. Ltd., Xi' an 710075, China. ${ }^{2}$ Key Laboratory of Degraded and Unused Land Consolidation Engineering, the Ministry of Natural Resources, Xi'an 710075, China. ${ }^{3}$ Shaanxi Provincial Land Consolidation Engineering Technology Research Center, Xi'an 710075, China. 
compaction, but also leads to waste of nutrient resources (Verchot et al. 2011). Organic fertilizer is rich in organic matter, contains a variety of nutrient elements, and has long-lasting effects, which can effectively improve soil structure, enhance soil microbial and enzyme activities, and increase soil fertility (Hati et al. 2007, Liu et al. 2019). Thus, organic fertilizer will help to optimize fertilization application practices and reduce the application of chemical fertilizer, which both play an important role in improving the quality of newly reclaimed farmland and protecting the environment (Zhao et al. 2013). Xin et al. (2016) found that the application of organic fertilizer significantly increases the content of water-stable macroaggregates, improves soil fertility, improve soil productivity, and maintains the sustainability of crop yields.

In the process of land consolidation, the surface soil and deeper soil are usually mixed and leveled, or even re-stacked, and the soil physicochemical properties change after covering with external soil are different from the mature soil that has been cultivated for many years, resulting in less soil maturity, low organic matter content, poor activity of microorganisms and enzymes, and fragile, unstable soil structure (Hu et al. 2010, Li et al. 2019a). Optimized fertilization application practices and reducing chemical fertilizer application can effectively improve soil structure, increase soil organic matter (SOM) content, and enhance the activity of soil microorganisms in the newly reclaimed cultivated land, which is conductive to accelerating the soil maturation and quality improvement of newly renovated cultivated land. At present, new technology based on environmental scanning electron microscopy (SEM) plays an important role in revealing the characteristics of soil microstructure and the dynamic evolution of soil quality (Jiang et al. 2014, Chang et al. 2015). Further study on soil microstructure using SEM will be helpful for understanding the mechanism of changes to soil properties (Lin and Cerato 2014). However, few studies have been conducted on the microstructure characteristics of newly reclaimed cultivated land by comparing and analyzing different fertilization application practices from a microscopic point of view.

Studying the optimized fertilization application practices is very important for accelerating the maturation and quality improvement of newly reclaimed cultivated soil; however, information on the influence of different fertilizer practices in newly reclaimed soil is scarce, especially from the microscopic perspective. Therefore, the present study was undertaken to evaluate effects of three different fertilization application practices on soil organic matter, cation exchange capacity, aggregate distribution, stability, soil bulk density, and soil water content in newly reclaimed cultivated land, soil microstructure characteristics under three different fertilization application practices using SEM and the correlation between SOM, $R_{0.25}$, MWD, and GMD.

\section{Materials and Methods}

This research was conducted in Chuyuan Village, Fuping County, Shaanxi Province, China $\left(34^{\circ} 42^{\prime} \mathrm{N}, 109^{\circ} 12^{\prime} \mathrm{E}\right)$. The study area belongs to the gully area of the Weibei Loess Plateau, and the climate is continental temperate, semi-arid, and semi humid. The annual average temperature, average sunshine hours, and total annual solar radiation are $13.4^{\circ} \mathrm{C}, 2,389.6 \mathrm{hrs}$ and $123.9-127.8$ $\mathrm{kcal} / \mathrm{cm}^{2}$, respectively. The dry and wet seasons are distinct, and natural conditions can meet the growth needs of crops. The soil in this region is loessial soil and was newly-reclaimed after land consolidation; therefore, the soil has less soil maturity and poor soil structure. The basic physicochemical properties of tested soil samples were as follows: the texture type is silt loam soil (USDA), which is composed of sand $(0.05-2.0 \mathrm{~mm})$, silt $(0.002-0.05 \mathrm{~mm})$, and clay $(<0.002$ $\mathrm{mm}$ ) accounted for $17.06,75.38$ and $7.56 \%$ of the total soil, respectively; $\mathrm{pH}$ value, 8.20 ; conductivity, $284 \mathrm{us} / \mathrm{cm}^{1}$; CEC, $8.90 \mathrm{cmol} / \mathrm{kg}$; organic matter content, $6.78 \mathrm{~g} / \mathrm{kg}$, available phosphorus content, $6.5 \mathrm{mg} / \mathrm{kg}$ and available potassium content, $101.9 \mathrm{mg} / \mathrm{kg}$. 
This study was conducted as a pot experiment and different fertilization experiments in a scientific research greenhouse were initiated in July 2016. The pot size was $48 \mathrm{~cm}$ in diameter at the top, $36 \mathrm{~cm}$ in diameter at the bottom, and $42 \mathrm{~cm}$ in height. The pots were equipped with ventilating pipes at the edges of the pot, and each pot contained approximately $40 \mathrm{~kg}$ of soil. Three fertilization application practices were conducted in this experiment: organic fertilizer practice (OF), organic fertilizer combined with chemical fertilizer practice (OC), and conventional fertilization practice $(\mathrm{CF})$. Each treatment had six replicates. Only chemical fertilizers were used in the $\mathrm{CF}$ practice, $70 \%$ organic fertilizer combined with $30 \%$ chemical fertilizer was used in the OC practice, and only organic fertilizer was used in the OF practice. Chemical fertilizer included urea, diammonium phosphate, and potassium sulfate, whereas organic fertilizer used locally decomposed sheep dung. The amount of fertilizer was based on the recommended amount of fertilizer used for local agricultural practices, and the $\mathrm{N}$, P, and $\mathrm{K}$ content of organic fertilizers were determined before fertilization. The same total nitrogen content $\left(240 \mathrm{~kg} \mathrm{hm}^{-2}\right)$ was utilized in all fertilizer applications in the three fertilization application practices; all organic, phosphorus, and potassium fertilizers were applied as basal fertilizer. For all treatments, $50 \%$ of the total nitrogen fertilizer was applied as a basal fertilizer and the other $50 \%$ of nitrogen fertilizer was applied as top dressing at different plant growth stages. Other management practices, such as water supply and pest control, were consistent across the three treatments. The cropping system was a rape-corn rotation system, an artificial sowing method was used, organic and chemical fertilizers were evenly spread on the soil surface before sowing, and then organic fertilizer and chemical fertilizer were incorporated into the top $0-20 \mathrm{~cm}$ of soil through tillage.

After the corn was harvested at the end of September 2019, disturbed and undisturbed soil samples were collected at $0-10 \mathrm{~cm}$ and $10-20 \mathrm{~cm}$ to determine soil bulk density, soil moisture content, aggregates, organic matter, and other physicochemical properties. Impurities, such as roots and gravel from the soil and minimized human interference during the transportation of soil samples were removed to avoid impact on soil structure. Soil microstructure features were characterized using an FEI Q45 SEM produced by the American FEI company. When conducting the SEM experiment, air-dried soil samples were coated with an ion sputter instrument to obtain a better flat surface, and then microstructure characteristics were observed at a voltage of $10 \mathrm{kV}$ with 100 and 1,000 X magnification. The content of clay and silt was measured by the pipette method, soil bulk density was determined using cutting ring method, and soil moisture content was determined by the gravimetric method (Rabot et al. 2018, Xue et al. 2019). SOM was measured by the rapid dichromate oxidation method and cation exchange capacity was measured with a flame atomic absorption spectrophotometer (Tiessen and Moir 1993, Sun et al. 2020). The stability and size distribution of soil aggregates in the $0-20 \mathrm{~cm}$ soil layer were measured using the wet-sieve and dry-sieving method, respectively (Nimmo and Perkins 2002, Six et al. 2004). The proportion of $>0.25 \mathrm{~mm}$ aggregates $\left(R_{0.25}\right)$, mean weight diameter (MWD), geometric mean diameter (GMD), and fractal dimension $(D)$ were calculated as equations $1,2,3$, and 4, respectively (Karami et al. 2012, Zhu et al. 2017).

$$
\begin{aligned}
& R_{0.25}=\frac{M_{r}>0.25}{M_{T}}=1-\frac{M_{r} \leq 0.25}{M_{T}} \\
& \mathrm{MWD}=\frac{\sum_{i=1}^{n}\left(\bar{x}_{i} w_{i}\right)}{\sum_{i=1}^{n} w_{i}}
\end{aligned}
$$




$$
\begin{gathered}
\mathrm{GMD}=\exp \left(\frac{\sum_{i=1}^{n} w_{i} \ln \bar{x}_{i}}{\sum_{i=1}^{n} w_{i}}\right) \\
\frac{M\left(r<\bar{x}_{i}\right)}{M_{T}}=\left(\frac{\bar{x}_{i}}{x_{\max }}\right)^{3-D}
\end{gathered}
$$

The data were processed and analyzed by Microsoft Excel 2010 and SPSS 22.0. Figure generation was performed by using SigmaPlot12.5. The location map was produced using ESRI ArcGIS software. A one-way analysis of variance of experimental data was conducted using SPSS 22.0 and the LSD method was used for multiple comparisons. Differences were considered significant at $\mathrm{p}<0.05$. Some micromorphological features were qualitatively described and compared by careful observation of SEM images.

\section{Results and Discussion}

Compared with CF, OF and OC significantly increased SOM content and CEC of newly reclaimed cultivated soil in the $0-10 \mathrm{~cm}$ and $10-20 \mathrm{~cm}$ soil layers $(\mathrm{p}<0.05)$. The SOM content and $\mathrm{CEC}$ under the three fertilization application practices had the following order $\mathrm{CF}<\mathrm{OC}<\mathrm{OF}$ (Fig. 1). Compared with the CF practice, the SOM content under OF and OC was increased by 46.2 and $36.1 \%$ at a soil depth of $0-10 \mathrm{~cm}$, respectively, and $\mathrm{OF}$ and $\mathrm{OC}$ were significantly different from CF. The SOM content in the OF practice was the highest, up to $12.67 \mathrm{~g} / \mathrm{kg}$. In the $10-20 \mathrm{~cm}$ soil layer, the SOM content under OF and OC was 59.3 and $29.6 \%$ higher than that under CF, respectively, and the minimum SOM content under CF was $7.08 \mathrm{~g} / \mathrm{kg}$ (Fig. 1a). The change in the CEC value showed a similar trend with the change of SOM content, and the difference between $\mathrm{OF}$ and $\mathrm{CF}$ was significant. In the $0-10 \mathrm{~cm}$ soil layer, the CEC under OF and OC was increased by 13.5 and 5.2\%, respectively, compared with the CF practice, and the highest CEC values under OF were $10.68 \mathrm{cmol} / \mathrm{kg}$. The CEC in the OF and OC practices increased by 10.6 and $4.1 \%$, respectively, compared with that in the CF practice at a depth of $10-20 \mathrm{~cm}$. The minimum CEC value in the CF practice was $9.09 \mathrm{cmol} / \mathrm{kg}$ (Fig. 1b).

The composition of water-stable aggregates in the newly reclaimed cultivated soil is an important indicator for evaluating soil structural stability and erosion resistance. Compared with $\mathrm{CF}$, OF significantly promoted the formation of $>5 \mathrm{~mm}, 2-5 \mathrm{~mm}, 1-2 \mathrm{~mm}, 0.5-1.0 \mathrm{~mm}$, and $0.25-0.5 \mathrm{~mm}$ water-stable aggregates, and decreased the proportion of $<0.25 \mathrm{~mm}$ water-stable aggregates in the $0-10 \mathrm{~cm}$ soil layer $(\mathrm{p}<0.05)$. The proportion of $2-5 \mathrm{~mm}$ and $1-2 \mathrm{~mm}$ soil aggregates increased significantly in the OC practice compared with the CF practice, but there was no significant difference in other particle-size aggregates. The proportion of water-stable macroaggregates $\left(R_{0.25}\right)$ in the OF and OC practices increased by 148.3 and $40.9 \%$, respectively, compared with that under CF. The proportion of $\mathrm{R}_{0.25}$ in the OF practice was the highest, which was significantly different from that under the OC and CF practices ( $p<0.05)$. In the $10-20 \mathrm{~cm}$ soil layer, the different particle-size aggregates in the $\mathrm{OF}$ and $\mathrm{OC}$ practices also had significant differences compared with $\mathrm{CF}$ (Fig. 2). The proportion of $\mathrm{R}_{0.25}$ in the $\mathrm{OF}$ and $\mathrm{OC}$ practices increased by 138.2 and $88.0 \%$, respectively, compared with the CF practice, and there was no significant difference between $\mathrm{OF}$ and $\mathrm{OC}$. 


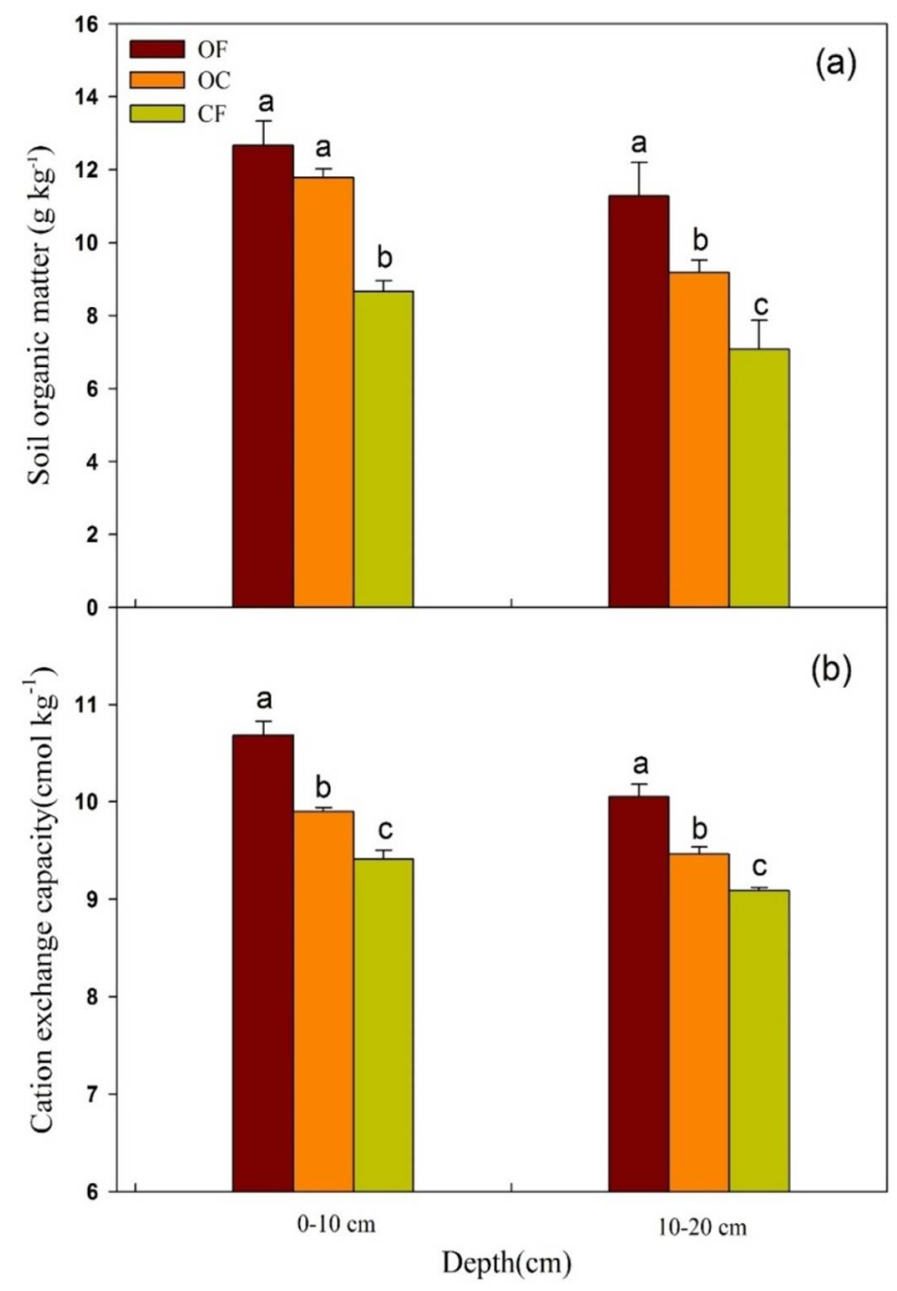

Fig. 1. Effects of different fertilization application practices on SOM and CEC at a soil depth of $0-20 \mathrm{~cm}$. CF: conventional fertilization practice; OC: organic fertilizer combined with chemical fertilizer practice; OF: organic fertilizer practice; SOM, soil organic matter; CEC, cation exchange capacity. Different lowercase letters represent significant differences between different fertilization application practices in the same soil layer.

From the observation and comparison of SEM images under different fertilization application practices, the soil microstructure of newly reclaimed soil underwent significant changes (Fig. 3). Under CF, the soil structure was mainly composed of moderately separated block and angular structures, and the pore types were mainly surface cracks and simple packing voids, with few plant residues (Fig. 3a). Soil aggregate development was relatively weak, the amount of compound packing pores and $>0.25 \mathrm{~mm}$ macroaggregates was small, whereas the amount of $<0.25 \mathrm{~mm}$ microaggregates and simple packing voids were large (Fig. 3d). In the OC practice, the main types soil microstructures were changed to moderately separated block structures and a small amount of highly developed agglomerate structures. The agglomeration and cementation between soil particles gradually increased, and the amount of $>0.25 \mathrm{~mm}$ macroaggregates and composite 
accumulation packing pores gradually increased (Fig. 3b). Moreover, the particle-size of aggregates gradually increased, with a small amount of well-developed macroaggregates and fresh plant residues (Fig. 3e). In the OF practice, the soil was mainly composed of highly developed granular structures, and more plant residues and well-developed aggregates were observed (Fig. $3 c)$. The soil agglomeration capability was further enhanced with the increase of SOM content, the microaggregates gradually agglomerated and formed well-developed macroaggregates, and a large number of composite accumulation pores appeared in the newly reclaimed soil (Fig. 3f).

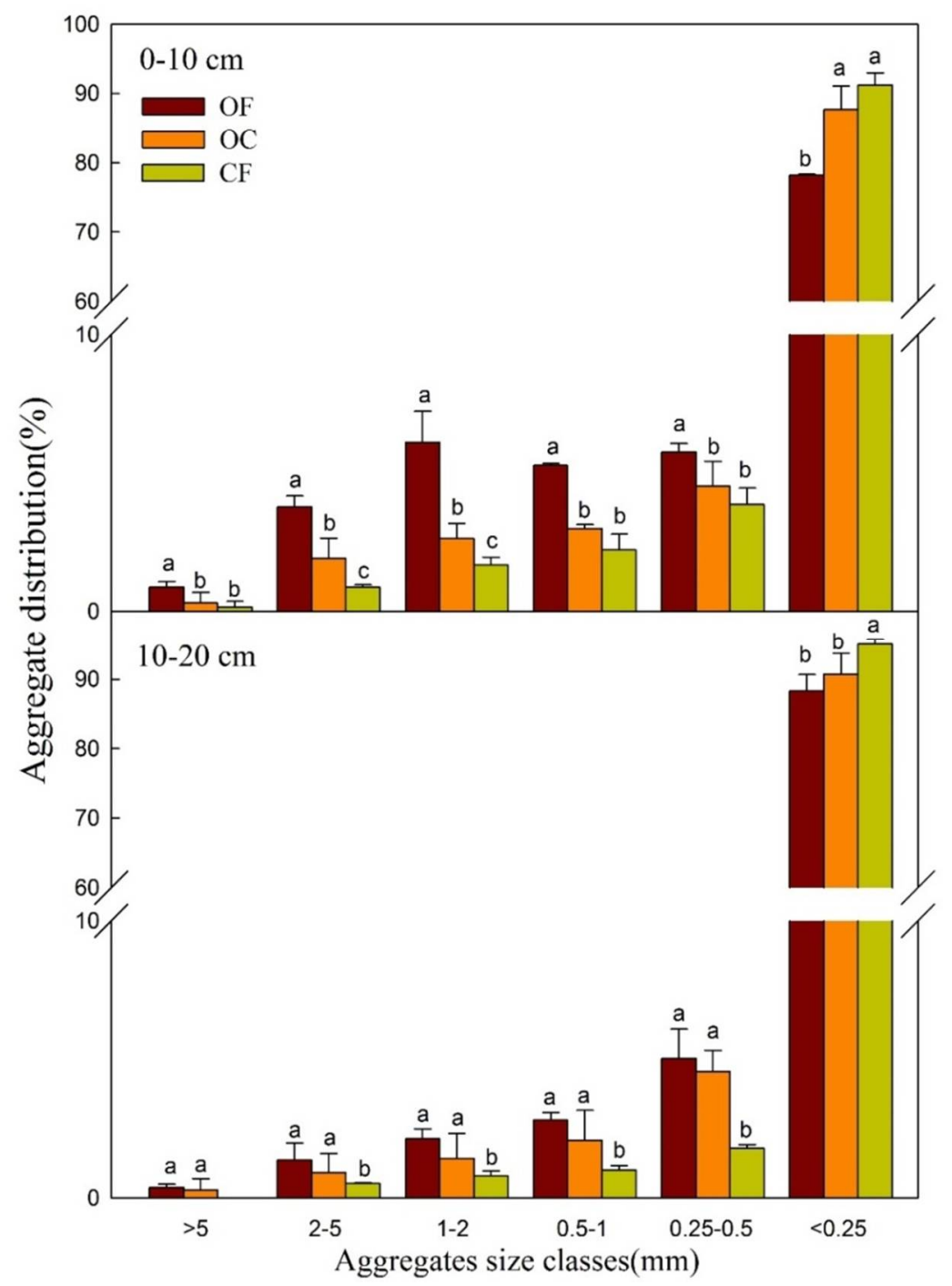

Fig. 2. Soil water-stable aggregates as affected by different fertilization application practices at $0-20 \mathrm{~cm}$ depth. $\mathrm{CF}$ : conventional fertilization practice; OC: organic fertilizer combined with chemical fertilizer practice; OF: organic fertilizer practice; $R_{0.25},>0.25 \mathrm{~mm}$ water-stable macroaggregates. Different lowercase letters represent significant differences between different fertilization application practices under same particle-size aggregates in the same soil layer. 


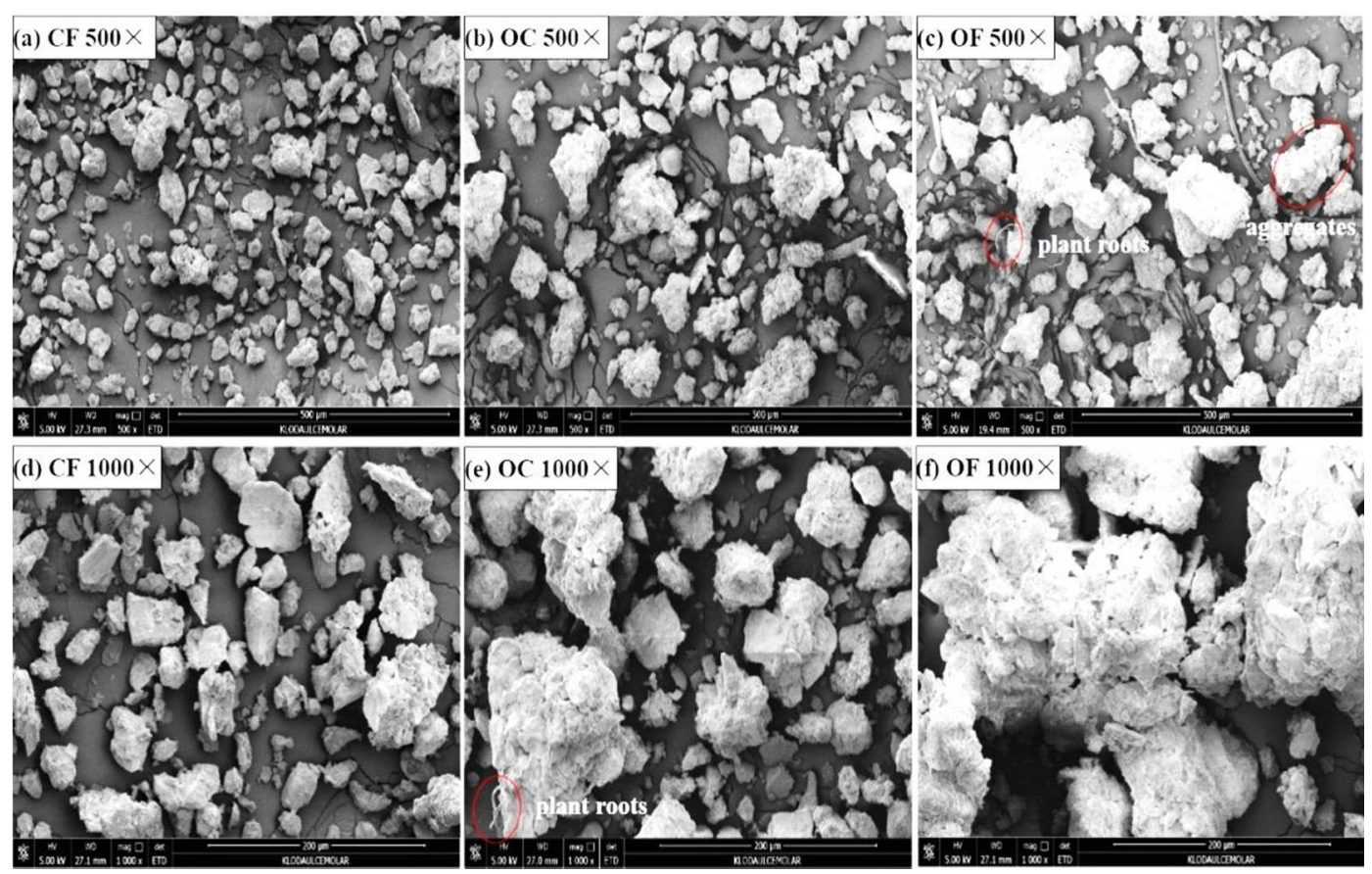

Fig. 3. SEM images of soil under different fertilization application practices.

The aggregate stability index showed that the MWD, GMD, and $R_{0.25}$ values in the OC and OF practices were higher than those under CF; in addition $D$ was less in the OC and OF practices than in the CF in the $0-10 \mathrm{~cm}$ and $10-20 \mathrm{~cm}$ soil layers (Table 1). The results from the wet-sieve method showed that in the $0-10 \mathrm{~cm}$ soil layer, the values of MWD, GMD, and $R_{0.25}$ in the OF practice were $62.5,21.4$ and $148.3 \%$ higher than those in the CF practice, the $D$ value was $1.7 \%$ lower than that in the $\mathrm{CF}$ practice, and the difference between $\mathrm{OF}$ and $\mathrm{CF}$ was significant ( $\mathrm{p}<$ 0.05 ). The values of MWD, GMD, and $R_{0.25}$ in the OC practice were 18.8, 3.6 and $40.9 \%$ higher than those in the $\mathrm{CF}$ practice, respectively, the $D$ value was $0.3 \%$ lower than that in the $\mathrm{CF}$ practice, and there was a significant difference in $R_{0.25}$ between OC and CF. In the $10-20 \mathrm{~cm}$ soil layer, the values of MWD, GMD, and $R_{0.25}$ in the OF practice were 28.6, 11.5 and $138.2 \%$ higher than those in the CF practice, respectively, the $D$ value was $0.3 \%$ lower than that of the CF practice, and a significant difference was found in MWD and $R_{0.25}$ between OF and CF. The values of MWD, GMD, and $R_{0.25}$ under OC were $17.8,7.7$ and $88.0 \%$ greater than those in the CF practice, the $D$ value was $0.3 \%$ lower than that in the CF practice, and there were significant differences in the MWD and $R_{0.25}$ values between the OC and CF practices ( $\mathrm{p}<0.05$ ). The results of aggregate stability obtained using the dry-sieving method showed a similar trend to that obtained using the wet-sieving method. Compared with the CF practice, the OC and CF practices both increased MWD, GMD, and $R_{0.25}$, and reduced the $D$ value. The effect of different fertilization application practices on the structural stability of aggregates in the $0-10 \mathrm{~cm}$ soil layer was higher than that in $10-20 \mathrm{~cm}$ soil layer, and soil aggregate stability in the newly reclaimed soil was the best in the OF practice. 
Table 1. Comparison of different fertilization application practices on the aggregate stability index.

\begin{tabular}{lllccc}
\hline Method & Index & Depth & \multicolumn{1}{c}{ OF } & OC & CF \\
\hline Wet-sieving & MWD(mm) & $0-10$ & $0.52 \pm 0.01 \mathrm{a}$ & $0.38 \pm 0.08 \mathrm{~b}$ & $0.32 \pm 0.02 \mathrm{~b}$ \\
& $10-20$ & $0.36 \pm 0.03 \mathrm{a}$ & $0.33 \pm 0.02 \mathrm{a}$ & $0.28 \pm 0.01 \mathrm{~b}$ \\
& GMD(mm) & $0-10$ & $0.34 \pm 0.01 \mathrm{a}$ & $0.29 \pm 0.02 \mathrm{~b}$ & $0.28 \pm 0.01 \mathrm{~b}$ \\
& $10-20$ & $0.29 \pm 0.01 \mathrm{a}$ & $0.28 \pm 0.01 \mathrm{a}$ & $0.26 \pm 0.01 \mathrm{a}$ \\
& & $0-10$ & $2.93 \pm 0.01 \mathrm{~b}$ & $2.97 \pm 0.02 \mathrm{a}$ & $2.98 \pm 0.01 \mathrm{a}$ \\
& & $10-20$ & $2.98 \pm 0.01 \mathrm{a}$ & $2.98 \pm 0.01 \mathrm{a}$ & $2.99 \pm 0.01 \mathrm{a}$ \\
& & $0-10$ & $21.80 \pm 0.14 \mathrm{a}$ & $12.37 \pm 3.44 \mathrm{~b}$ & $8.78 \pm 1.75 \mathrm{c}$ \\
& & $10-20$ & $11.72 \pm 2.40 \mathrm{a}$ & $9.25 \pm 3.04 \mathrm{a}$ & $4.92 \pm 0.71 \mathrm{~b}$ \\
& & $0-10$ & $2.06 \pm 0.04 \mathrm{a}$ & $1.96 \pm 0.02 \mathrm{~b}$ & $1.92 \pm 0.04 \mathrm{~b}$ \\
& & $10-20$ & $1.89 \pm 0.06 \mathrm{a}$ & $1.82 \pm 0.04 \mathrm{a}$ & $1.70 \pm 0.01 \mathrm{~b}$ \\
& & $0-10$ & $1.25 \pm 0.06 \mathrm{a}$ & $1.13 \pm 0.03 \mathrm{~b}$ & $1.11 \pm 0.05 \mathrm{~b}$ \\
& & $10-20$ & $1.08 \pm 0.14 \mathrm{a}$ & $1.05 \pm 0.04 \mathrm{a}$ & $0.96 \pm 0.06 \mathrm{a}$ \\
& & $0-10$ & $2.47 \pm 0.03 \mathrm{~b}$ & $2.52 \pm 0.01 \mathrm{a}$ & $2.53 \pm 0.02 \mathrm{a}$ \\
& & $10-20$ & $2.54 \pm 0.06 \mathrm{a}$ & $2.57 \pm 0.02 \mathrm{a}$ & $2.60 \pm 0.05 \mathrm{a}$ \\
& & $0-10$ & $82.15 \pm 2.19 \mathrm{a}$ & $77.95 \pm 2.10 \mathrm{~b}$ & $77.85 \pm 0.60 \mathrm{~b}$ \\
& & $10-20$ & $78.85 \pm 1.99 \mathrm{a}$ & $77.74 \pm 0.64 \mathrm{a}$ & $74.95 \pm 0.11 \mathrm{~b}$ \\
\hline
\end{tabular}

CF: conventional fertilization practice; OC: organic fertilizer combined with chemical fertilizer practice; OF: organic fertilizer practice; MWD, mean weight diameter; GMD, geometric mean diameter; $D$, fractal dimension; $R_{0.25},>0.25 \mathrm{~mm}$ water-stable macroaggregates. Different lowercase letters represent significant differences between different fertilization application practices in the same soil layer.

The bulk density (BD) in the $\mathrm{OF}$ and $\mathrm{OC}$ practices in the newly reclaimed soil were significantly lower than that under CF at soil depths of $0-10$ and $10-20 \mathrm{~cm}$ (Fig. $4 \mathbf{a}, \mathrm{p}<0.05$ ). In the $0-10 \mathrm{~cm}$ soil layer, the $\mathrm{BD}$ in the $\mathrm{OF}$ and $\mathrm{OC}$ practices was 10.6 and $4.4 \%$ less than that in the CF practice, respectively. The minimum BD in the OF practice was $1.21 \mathrm{~g} \mathrm{~cm}^{-3}$, and the differences among the OF, OC, and CF practices were significant ( $<<0.05)$. In the $10-20 \mathrm{~cm}$ soil layer, the $\mathrm{BD}$ showed the same decreasing trend. The BD in the OF and OC practices was 6.7 and $4.8 \%$ less than that in the $\mathrm{CF}$, respectively, and the $\mathrm{BD}$ in the $\mathrm{CF}$ practice was up to $1.40 \mathrm{~g} / \mathrm{cm}^{3}$. These results indicated that the $\mathrm{OF}$ and $\mathrm{OC}$ practices all reduced the $\mathrm{BD}$ and yielded a lower $\mathrm{BD}$ in the surface layer than in the bottom layer. The OF practice had the best effect on reducing BD.

The soil moisture content (SMC) under different fertilization application practices showed the following order: $\mathrm{OF}>\mathrm{OC}>\mathrm{CF}$ at depths of $0-10$ and $10-20 \mathrm{~cm}$ (Fig. 4b). The SMC in the OF and OC practices were 38.3 and $8.0 \%$, respectively, higher than that in the CF practices at a soil depth of 0-10 cm; the SMC in the OF practice was up to $17.8 \%$, and the OF and OC practices were significantly different from CF ( $p<0.05)$. In the $10-20 \mathrm{~cm}$ soil layer, the SMC in the OF and OC practice were 31.9 and $7.9 \%$ more than that under $\mathrm{CF}$, respectively; the difference between $\mathrm{OF}$ and $\mathrm{CF}$ was significant $(\mathrm{p}<0.05)$. The results showed that $\mathrm{OF}$ and $\mathrm{OC}$ could effectively improve the SMC of newly reclaimed soil while improving soil structure compared with $\mathrm{CF}$. 


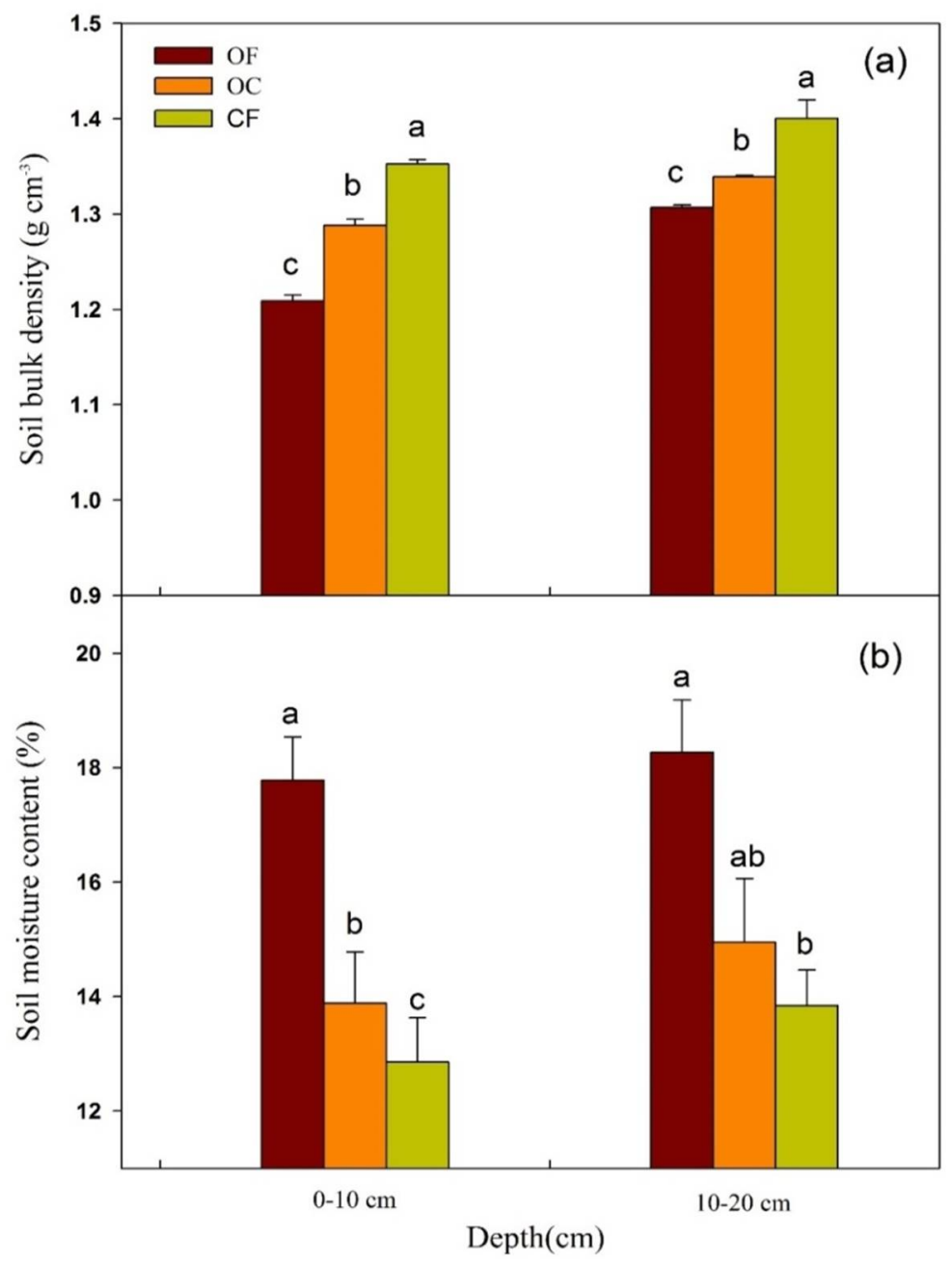

Fig. 4. Effects of different fertilization application practices on BD and SMC as shown at a soil depth of 0 $20 \mathrm{~cm}$. CF: conventional fertilization practice; OC: organic fertilizer combined with chemical fertilizer practice; OF: organic fertilizer practice; BD, soil bulk density; SMC, soil moisture content. Different lowercase letters represent significant differences between different fertilization application practices in the same soil layer.

There was a significant positive correlation between SOM content and MWD as well as GMD (Fig. 5; MWD, $R^{2}=0.6610, \mathrm{p}<0.0001 ; \mathrm{GMD}, R^{2}=0.6275, \mathrm{p}<0.0001$ ), and $R_{0.25}$ was also positively correlated with MWD as well as GMD in the newly reclaimed soil (MWD, $R^{2}=0.9738$, $\left.\mathrm{p}<0.0001 ; \mathrm{GMD}, R^{2}=0.9759, \mathrm{p}<0.0001\right)$. The results from the correlation analysis indicate that SOM increased with the application of exogenous organic fertilizer, which promoted the formation of water-stable microaggregates, and SOM content was positively correlated with the proportion of $R_{0.25}\left(R^{2}=0.7167, \mathrm{p}<0.0001\right)$. With the increase of SOM content and the proportion of $R_{0.25}$, the GMD and MWD values of water-stable aggregates also increased, which promoted the agglomeration of soil particles, improving the stability of water-stable aggregates and the soil structure (Fig. 5). 

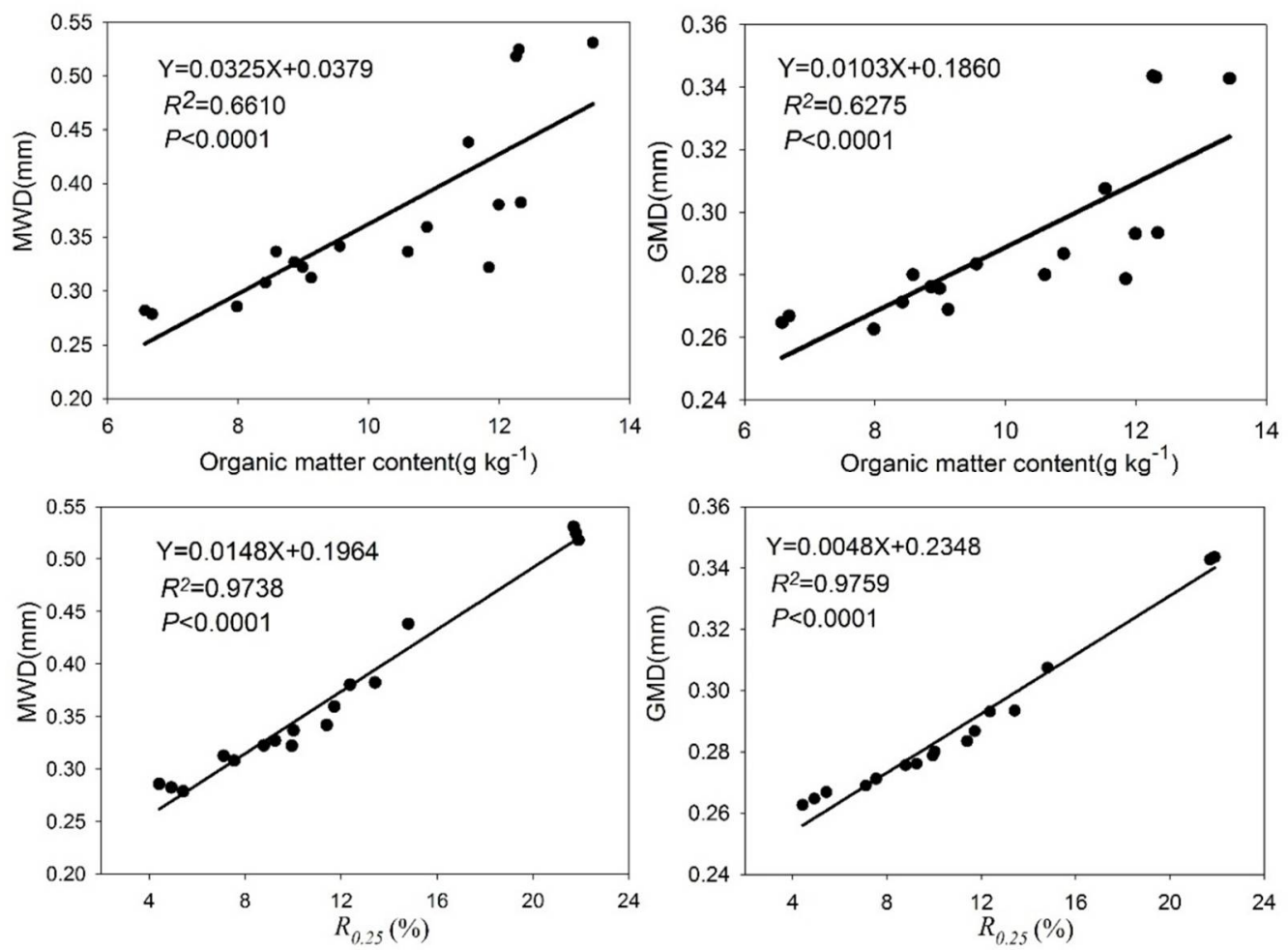

Fig. 5. The correlation between SOM, $R_{0.25}$, MWD, and GMD. CF: conventional fertilization practice; OC: organic fertilizer combined with chemical fertilizer practice; OF: organic fertilizer practice; SOM, soil organic matter; $\mathrm{R}_{0.25},>0.25 \mathrm{~mm}$ water-stable macroaggregates; MWD, mean weight diameter; GMD, geometric mean diameter.

Results of the present study are consistent with studies conducted by Cai et al. (2015) and Song et al. (2015), who showed that the application of exogenous organic fertilizer was beneficial to the increase of CEC and SOM. In the CF practice, since there was no application of additional organic matter, and long-term application of chemical fertilizers it may lead to the selective absorption of different charged ions by crops and the difference in soil adsorption may increase the loss of soil cations, resulting in lower SOM content and CEC in newly reclaimed soil (Verchot et al. 2011).

Results of the study are more of less similar to the reresults reported by Celik et al. (2010), who found that compared with single application of chemical fertilizers, the application of exogenous organic fertilizers significantly reduced BD and penetration resistance, whereas it increased soil porosity (Zhou et al. 2013). The increase in the SOM content resulting from the application of organic fertilizers was beneficial to the formation of soil aggregates, the improvement of structural stability, and the increase in soil porosity and water infiltration capacity in the newly reclaimed soil. Moreover, the capacity of soil organic matter to absorb water is much greater than that of soil minerals, which is beneficial to improve the soil water retention capacity, thereby increasing the soil moisture content (Horn et al. 1994). Similarly, Ranjan et al. (2008) and Zhou et al. (2016) reported that the application of organic fertilizer can effectively enhance the soil water holding capacity. 
Results of the present study are similar to the results presented by Meng et al. (2014), who found that the application of exogenous organic fertilizers had an important influence on the distribution and quantity of soil aggregates, which could significantly increase the proportion of water-stable macroaggregates and aggregate stability.

The SEM images of the soil microstructure showed that simple pores and surface fissures mainly existed in the soil with poor structure and less maturity (Fig. 3). The SOM derived from organic fertilizers under OF and OC may enhance the activity of roots and organisms in the soil to produce cementing agents, such as polysaccharides and exudates, and stimulate the formation of well-developed aggregates and composite accumulations pores. Besides, these factors are beneficial for improving the structural stability and quantity of soil aggregates (Sodhi et al. 2009, Tripathi et al. 2014). However, the CF practice likely accelerated the mineralization and decomposition of organic matter due to the long-term single application of chemical fertilizers without the input of external organic matter, resulting in a substantial decrease in SOM content and binding agents (Tisdall and Oades 1982, Zhang et al. 2016). In the present study, CF caused deterioration and fragmentation of aggregate structure, and reduced the proportion of macroaggregates, compared to the $\mathrm{OF}$ practice. The $\mathrm{CF}$ practice also resulted in weakening capability of soil aggregation and recombination. This might be due to the degradation and depletion of SOM. The breakdown of aggregates led to the decrease of SOM and had a negative impact on the improvement of pore structure and soil structural stability (Ashagrie et al. 2007).

MWD, GMD, $R_{0.25}$, and $D$ are important indicators reflecting the distribution and stability of soil aggregates, where higher MWD, GMD, and $R_{0.25}$ values and lower $D$ values indicate better soil agglomeration capability and stability (Cremeens 2004, Wang et al. 2013). In this study, the $\mathrm{OF}$ and $\mathrm{OC}$ practices both enhanced soil agglomeration and stability compared to the CF practice, and have a positive effect on the improvement of soil structure and fertility. The OF practice had the best effect on soil agglomeration and stability, which was consistent with the results displayed by SEM images (Fig. 4). Previous studies have also demonstrated that the formation and stability of soil aggregates appears to be closely linked to SOC content (Bronick and Lal 2005, Mikha et al. 2015). More organic fertilizer was applied in OF than in OC; therefore, the increase in organic fertilizer likely led to the higher organic matter content in OF, which had a more positive effect on aggregate stability than the OC practice. The results are partially consistent with the results reported by Zhao et al. (2011), who found that the application of exogenous organic fertilizer to cinnamon soil increased the macroaggregate content and aggregate stability, and the effect of organic fertilizer practice was better than that of organic fertilizer combined with chemical fertilizer.

There were significant positive correlations between SOM content, $R_{0.25}$, and GMD as well as MWD, which showed that as SOM content increased with the application of additional organic fertilizers, the $R_{0.25}$, GMD, and MWD values also increased, improving the structural stability of aggregates. The present results are supported by the results presented by Chivenge et al. (2011) and Wang et al. (2013) who showed that the application of additional organic fertilizers promoted the formation of water-stable macroaggregates and the improvement of aggregate stability increased the GMD and MWD values, ultimately improving soil structural stability. The OF and OC practices were associated with significant increases in SOM content and CEC of newly reclaimed cultivated soil which could enhance the effect on the macroaggregate content and aggregate stability. Therefore, the application of $\mathrm{OF}$ and $\mathrm{OC}$ generally have a positive effect on improving soil fertility and structural stability in newly reclaimed cultivated land.

Compared with the CF practice, the OF and OC practices significantly increased the SOM content and CEC of newly reclaimed cultivated soil, which promoted the formation of water-stable macroaggregates and the improvement of soil structure. The soil microstructure changed from 
moderately separated angular structures to moderately separated block structures and highly developed granular structures, with more composite accumulation pores and well-developed macroaggregates. Greater soil improvement was observed in the OF practice. The OF and OC practices were also associated with higher SMC, $R_{0.25}$, GMD, and MWD values, and lower $\mathrm{BD}$ and $D$ values, which demonstrated that the application of organic matter inputs increased aggregate stability and improved soil physical properties. Moreover, there were significant positive correlations between SOM content, $R_{0.25}$ and GMD as well as MWD, indicating that as SOM content increased with the use of additional organic fertilizers, the $R_{0.25}, \mathrm{GMD}$, and MWD values also increased, ultimately supporting good soil structural stability. In conclusion, these results confirm the benefits of OF and OC on the soil structural stability and water and fertilizer retention characteristics, which will be of great significance in promoting the health and sustainable development of newly reclaimed cultivated land.

\section{Acknowledgements}

This research was supported by the Scientific Research Item of Shaanxi Provincial Land Engineering Construction Group(DJNY2020-25), Shaanxi Province Innovative Talent Promotion Plan (Youth Science and Technology Rising Star Project) (2020KJXX-051), and the 2018 Open Fund for Shaanxi Key Laboratory of Land Remediation(2018-TD02).

\section{References}

Ashagrie Y, Zech W, Guggenberger G and Mamo T 2007. Soil aggregation, and total and particulate organic matter following conversion of native forests to continuous cultivation in Ethiopia. Soil Tillage Res. 94(1): 101-108.

Bronick CJ, Lal R 2005. Soil structure and management: a review. Geoderma(1-2) 124: 3-22.

Cai ZJ, Wang BR, Xu MG, Zhagn HM, He XH, Zhagn L and Gao SD 2015. Intensified soil acidification from chemical $\mathrm{N}$ fertilization and prevention by manure in an 18-year field experiment in the red soil of southern China. J Soil Sediment. 15(2): 260-270.

Celik I, Gunal H, Budak M and Akpinar C 2010. Effects of long-term organic and mineral fertilizers on bulk density and penetration resistance in semi-arid Mediterranean soil conditions. Geoderma 160(2): 236-243.

Chang I, Im J, Prasidhi AK and Cho GC 2015. Effects of Xanthan gum biopolymer on soil strengthening. Constr Build Mater. 74(15): 65-72.

Chang EH, Chung RS and Tsai YH 2010. Effect of different application rates of organic fertilizer on soil enzyme activity and microbial population. Soil Sci Plant Nutr. 53(2):132-140.

Chivenge P, Vanlauwe B, Gentile R and Six J 2011. Organic resource quality influences short-term aggregate dynamics and soil organic carbon and nitrogen accumulation. Soil Biol. Biochem. 43(3): 657-666.

Cremeens DL 2004. Guidelines for analysis and description of soil and regolith thin sections. Geoarchaeology 19: 507-509.

Doran JW and Zeiss MR 2000. Soil health and sustainability: Managing the biotic component of soil quality. Appl. Soil Ecol. 15(1): 3-11.

Hati KM, Swarup A, Dwivedi A, Misra A and Bandyopadhyay K 2007. Changes in soil physical properties and organic carbon status at the topsoil horizon of a vertisol of central india after 28 years of continuous cropping, fertilization and manuring. Agric. Ecosyst. Environ. 119(1): 127-134.

Horn R, Taubner H, Wuttke M and Baumgartl T 1994. Soil physical properties related to soil structure. Soil Tillage Res. 30(2-4): 187-216.

Hu SG, Wang J and Wang ZQ 2010. Characterization of quantity-quality grade conversion coefficient of supplementary cultivated land in Jianghan Plain, China. Proceedings of SPIE-The International society for Optical Engineering. 7841: 1-9. 
Jiang M, Zhang F, Hu H, Cui Y and Peng J 2014. Structural characterization of natural loess and remolded loess under triaxial tests. Engineering Geology. 181: 249-260.

Karami A, Homaee M, Afzalinia S, Ruhipour H and Basirat S 2012. Organic resource management: impacts on soil aggregate stability and other soil physico-chemical properties. Agr Ecosyst Environ. 148(4): 22-28.

Li H, Liu JH, Geng QM and Xu H 2019a. Study on soil erosion characteristics of new cultivated landin different opographic sites in low hilly areas. Forestry and Ecological Sciences. 34: 401-408.

Lin B and Cerato AB 2014. Applications of SEM and ESEM in microstructural investigation of shale-weathered expansive soils along swelling-shrinkage cycles. Ecol Eng. 177: 66-74.

Liu YS 2018. Introduction to land use and rural sustainability in China. Land Use Policy. 74: 1-4.

Liu YS, Li JT and Yang YY 2018. Strategic adjustment of land use policy under the economic transformation. Land Use Policy. 74: 5-14.

Liu YS, Long HJ, Chen YF, Wang JY, Li YR, Li YH, Yang YY and Zhou Y 2016. Progress of research on urbanrural transformation and rural development in China in the past decade and future prospects. $\mathrm{J}$ Geogr Sci. 26(8): 1117-1132.

Liu Z, Han JC, Sun ZH, Chen TQ, Hou Y, Dong QG, He J and Lv YZ 2019. Long-term effects of different planting patterns on greenhouse soil micromorphological features in the North China Plain. Sci. Rep-UK. 9(1): 1-10.

Meng QF, Sun YT, Zhang J, Zhou LR, Ma XF, Zhou M, Gao W and Wang GC 2014. Distribution of carbon and nitrogen in water-stable aggregates and soil stability under long-term manure application in solonetzic soils of the Songnen plain, northeast China. J. Soil Sediment. 14: 1041-1049.

Mikha MM and Rice CW 2014. Tillage and manure effects on soil and aggregate-associated carbon and nitrogen. Soil Sci. Soc. Am. J. 68(3): 809-816.

Mikha MM, Hergert GW, Benjamin JG, Jabro JD and Nielsen RA 2015. Long-term manure impacts on soil aggregates and aggregate-associated carbon and nitrogen. Soil Sci. Soc. Am. J. 79(2): 626-636.

Nimmo JR and Perkins KS 2002. Aggregates Stability and Size Distribution. In: Methods of Soil Analysis, Part4-Physical Methods. Soil Sci. SOM. Am. J. Inc. Madison, Wisconsin, USA 317-328.

Ranjan B, Kundu S, Prakash V, Gupta HS 2008. Sustainability under combined application of mineral and organic fertilizers in a rainfed soybean-wheat system of the Indian Himalayas. Eur. J. Agron. 28(1): 33-46.

Rabot E, Wiesmeier M, Schlüter S and Vogel HJ 2018. Soil structure as an indicator of soil functions: A review. Geoderma 314: 122-137.

Sainju UM 2006. Carbon and nitrogen pools in soil aggregates separated by dry and wet sieving methods. Soil Science. 171: 937-949.

Six J, Bossuyt H, Degryze S and Denef KA 2004: History of research on the link between (micro)aggregates, soil biota, and soil organic matter dynamics. Soil Tillage Res. 79(1): 7-31.

Sodhi GPS, Beri V and Benbi DK 2009. Soil aggregation and distribution of carbon and nitrogen in different fractions under long-term application of compost in rice-wheat system. Soil Tillage Res. 103(2): 412-418.

Song ZW, Zhu P, Gao HJ, Peng C, Deng AX, Zheng CY, Mannaf MA, Islam MN and Zhang WJ. 2015. Effects of long-term fertilization on soil organic carbon content and aggregate composition under continuous maize cropping in Northeast China. J. Agri. Sci. 153(2): 236-244.

Sun ZH, Han JC, Wang HY, Zhang RQ, Sun YY, Wei J and Hu Y 2020. Use and economic benefit of soft rock as an amendment for sandy soil in Mu Us Sandy Land, China. Arid Land Res Manag. 1532(1): 1-17.

Tiessen H and Moir JO 1993. Total and Organic Carbon. In:Carter, M.R. (Ed.), Soil Sampling and Methods of Analysis. J. Environ. Qual. 38: 187-199.

Tripathi R, Nayak AK, Bhattacharyya P, Shukla AK, Shahid M, Raja R, Panda BB, Mohanty S, Kumar A and Thilagam VK 2014. Soil aggregation and distribution of carbon and nitrogen in different fractions after 41 years long-term fertilizer experiment in tropical rice-rice system. Geoderma 213: 280-286. 
Tisdall J and Oades JM 1982. Organic matter and water-Stable aggregates in soils. Eur J Soil Sci. 33: 141-163.

Verchot L, Dutaur L, Shepherd KD and Alain A 2011. Organic matter stabilization in soil aggregates: Understanding the biogeochemical mechanisms that determine the fate of carbon inputs in soils. Geoderma 161: 182-193.

Wang F, Tong YA, Zhang JS, Gao PC and Cofe JN 2013. Effects of various organic materials on soil aggregate stability and soil microbiological properties on the Loess Plateau of China. Plant Soil Environ. 59(4): $162-168$.

Xin XL, Zhang JB, Zhu AN and Zhang CZ 2016. Effects of long-term (23 years) mineral fertilizer and compost application on physical properties of fluvo-aquic soil in the North China Plain. Soil Tillage Res. 156: $166-172$.

Xue B, Huang L, Huang Y, Yin Z, Li X and Lu J 2019. Effects of organic carbon and iron oxides on soil aggregate stability under different tillage systems in a rice-rape cropping system. Catena 177: 1-12.

Zhang ZY, Zhang XK, Mahamood MD, Zhang SQ, Huang SM and Liang WJ 2016. Effect of long-term combined application of organic and inorganic fertilizers on soil nematode communities within aggregates. Sci. Rep-UK 6(1): 31118.

Zhao H, Yuan PM, Lv YZ and Li J 2011. Effects of Organic Manure Application on Stability of Soil Aggregates. Soils 43(2): 306-311.

Zhao BZ, Chen J, Zhang JB, Xin XL and Hao XY 2013. How different long-term fertilization strategies influence crop yield and soil properties in a maize field in the North China Plain. J. Plant Nutr. Soil Sci. 176(1): 99-109.

Zhou H, Peng XH, Perfect E, Xiao TQ and Peng GY 2013. Effects of organic and inorganic fertilization on soil aggregation in an Ultisol as characterized by synchrotron based X-ray micro-computed tomography. Geoderma 195-196: 23-30.

Zhou H, Fang H, Mooney SJ and Peng XH 2016. Effects of long-term inorganic and organic fertilizations on the soil micro and macro structures of rice paddies. Geoderma 266: 66-74.

Zhu G, Shangguan Z and Deng L 2017. Soil aggregate stability and aggregate -associated carbon and nitrogen in natural restoration grassland and Chinese red pine plantation on the Loess Plateau. Catena 149: $253-260$.

(Manuscript received on 19 May, 2021, revised on 29 September, 2021) 